\title{
Structural Damage Detection by Using Finite Element Method as Function of Length
}

\author{
Djamel Bensahal ${ }^{1, \mathrm{a}}$, Mohamed Nadir Amrane ${ }^{1, \mathrm{~b}}$, Foued Chabane ${ }^{1, \mathrm{c}}$, Okba Belahssen ${ }^{2, \mathrm{~d}}$, \\ and Said Benramache ${ }^{2, e}$ \\ 1 Mechanics Department, Faculty of Sciences \&Technology, University of Biskra, Algeria \\ 2 Material Sciences Laboratory, Faculty of Science, University of Biskra, Algeria \\ E-mail: abensahaldjamel@yahoo.fr (Corresponding author),bmnamrane@yahoo.com,

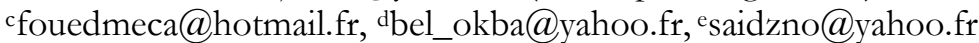

\begin{abstract}
The work concerned exactly a structural damage. In this paper also involves the effect of length on the damping of the composite. The calculation of laminate damping is performed by use of a strain energy method. The modal analysis of the structure for different loading rates is based on the analytical method used to solve the equation of free vibrations. The difference between strain energies for both cases (damaged and undamaged) are calculated by the finite element method. The structural damping of the different beams is evaluated from these energies. The results deduced from the damping by finite element analysis for the first three modes that the evaluation of laminate damping takes account the variation of the structural damping $\eta$ with lengths. This study shows clearly the decrease of one of dynamic characteristics especially the frequency when the loading rate increases for all lengths studied; this should have high utility as a decisive test for non-destructive damage detection.
\end{abstract}

Keywords: Structural damping, modal analysis, composites, finite element method, frequency.

ENGINEERING JOURNAL Volume 17 Issue 4

Received 3 January 2013

Accepted 10 April 2013

Published 1 October 2013

Online at http://www.engj.org/

DOI:10.4186/ej.2013.17.4.111 


\section{Introduction}

The increasing need for high-performance structures has stimulated considerable research in the characterization of damping in advanced composite materials. Helicopter rotor blades, turbine compressor blades and space structure truss elements are examples of aerospace applications of composites where damping properties are important. Damping is a measure of the energy dissipation in any vibrating structure. The progress has been achieved in the analysis and measurement of dynamic properties of composite materials. For example, closed -form solutions for dynamic stiffness and damping properties of laminated plates and laminated beams have been derived, and finite element methods have been used in both macro mechanical and micromechanical modeling $[1,3]$. Viscoelastic materials combine the capacity of an elastic type material to store energy with the capacity to dissipate energy. So, the use of an energy approach for evaluating the material or structure damping is widely considered. In this energy approach, the dissipated energy is related to the strain energy stored by introducing a damping parameter [4].

The initial works on the damping analysis of fibre composite materials were reviewed extensively in review paper by Gibson and Plunkett [5] and Gibson and Wilson [6]. A damping process has been developed initially by Adams and Bacon [7] who sees that energy dissipation can be described as separable energy dissipations associated to the individual stress components. This analysis was refined in later paper of $\mathrm{Ni}$ and Adams [8]. The damping of orthotropic beams is considered as function of material orientation and the papers also consider cross-ply laminates and angle-ply laminates, as well as more general types of symmetric laminates.

The damping concept of Adams and Bacon was also applied by Adams and Maheri [9] to the investigation of angle-ply laminates made of unidirectional glass fibre or carbon layers. The finite element analysis has been used by Lin et al. [10] and Maheri and Adams [11] to evaluate the damping properties of free-free fibre reinforced plates. These analyses were extended to a total of five damping parameters, including the two transverse shear damping parameters. More recently the analysis of Adams and Bacon was applied by Yim [12] and Yim and Jang [13] to different types of laminates, then extended by Yim and Gillespie [14] including the transverse shear effect in the case of $0^{\circ}$ and $90^{\circ}$ unidirectional laminates. For thin laminate structures the transverse shear effects can be neglected and the structure behavior can be analyzed using the classical laminate theory.

The natural frequencies and mode shapes of rectangular plates are well described using the Ritz method introduced by Young [15] in the case of homogeneous plates. The Ritz method was applied by Berthelot and Safrani [16] to describe the damping properties of unidirectional plates. The analysis was extended to the damping analysis of laminates [17]. In this study, we considered that there is the simplicity of calculations while assuming that the structure is subjected of free vibration and undamped. After each fatigue cycle, we have a new value of Young's modulus as reported in Fig. 1. Our assumption supposed that the material of each beam studied is homogeneous and it established a relation between the results of Young's modulus found experimentally that will be consequently injected into the model which is simple basing on the finite element method. The idea is to replacing the Young's modulus found experimentally in the equations of finite element method. Hence, we keep the same programs developed. This paper presents an evaluation of the structural damping as function of the length using finite element method for two materials with different sequences $\mathrm{U}$ and $\mathrm{C} 2$.

\section{Materials Tested}

The experimental study was achieved in the case of glass fibre composites. The experimental tests are realized in institute of acoustics and mechanics, university of Lemans, France. The laminate was prepared by hand lay-up process from SR1500 epoxy resin with SD2505 hardener and unidirectional E-glass fibre fabrics of weight $300\left(\mathrm{~g} / \mathrm{m}^{2}\right)$. The evaluation of damping was performed on beams of different lengths: 140,160, 180, 200, 210, 220, 230 and $240 \mathrm{~mm}$. Beams had a nominal width of $20 \mathrm{~mm}$, were cured at room temperature with a pressure of $30 \mathrm{kPa}$ using vacuum moulding process, and then post-cured for $8 \mathrm{~h}$ at $80^{\circ} \mathrm{C}$ in an oven. Beams had a nominal thickness of $2 \mathrm{~mm}$ with a volume fraction of fibres equal to 0.40 . The laminated beams with height lengths for each material are analyzed. The mechanical modulus of elasticity of the materials was measured in static tensile. Unidirectional composites have exceptional properties in the fibre direction and mediocre properties perpendicular to the fibre directions. There are very few situations where composites are used purely in a unidirectional configuration. In most applications there will be some 
form of loading away from the direction of the fibres. In this situation, it is only the resin that resists this load which has no reinforcement. Hence, composites structures are made by combining unidirectional laminates in different directions to resists these loads as material C2. Many products in a variety of industries are fabricated from composites, from fighter aircraft to bath tubs. There are more examples in different industries including: Automotive and rail, boating, general engineering, aerospace, sporting goods, civil engineering, domestic and medical. The mechanical characteristics of $\mathrm{U}$ and $\mathrm{C} 2$ materials are reported in Table 1.

Table 1. Mechanical characteristics of composite materials of $\mathrm{U}$ and C2.

\begin{tabular}{lccr}
\hline Material & Stacking Sequences & $\begin{array}{c}\text { Young's Modulus } \\
\text { (GPa) }\end{array}$ & $\begin{array}{r}\text { Max Load at } \\
\text { Fracture (KN) }\end{array}$ \\
\hline $\mathrm{U}$ & {$[(0)]_{8}$} & 21.08 & 35.165 \\
$\mathrm{C} 2$ & {$\left[(0 / 90)_{2}\right] \mathrm{s}$} & 15.04 & 20.915 \\
\hline
\end{tabular}

The experimental investigation was conducted using tensile cyclic tests for different laminates studied. The applied load ratio is $10 \%$ of maximum load failure. The loading rate is the ratio of the load relative to the maximum load failure. We divided the maximum force of rupture in ten equal parts $(10$ cycles), for each cycle the load is increased by $10 \%$ of the maximum load failure. After each fatigue cycle, we have a new value of Young's modulus as reported in Fig. 1. It established a relation between the results of Young's modulus found experimentally that will be consequently injected into the model which is simple basing on the finite element method. The idea is to replacing the Young's modulus found experimentally in the equations of finite element method. Hence, we keep the same programs developed. Fig. 1 shows the results obtained for the Young's modulus reduction as a function of cycle number.

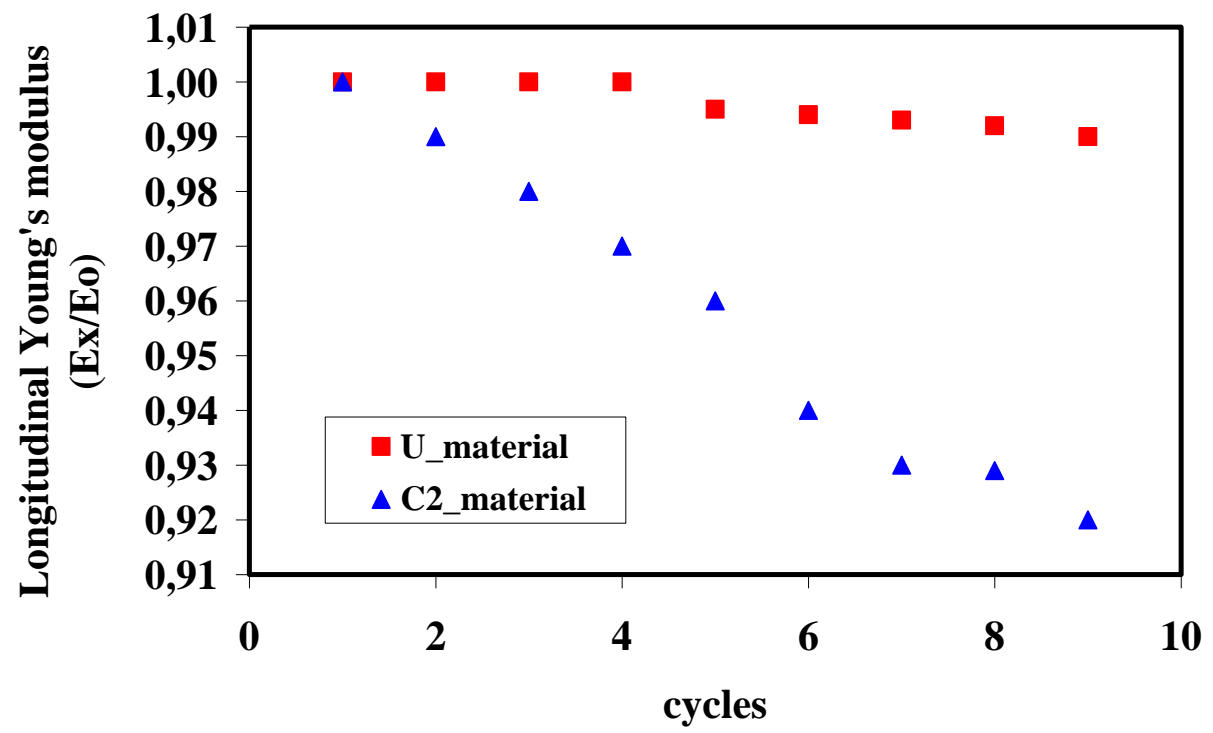

Fig. 1. Stiffness reduction of two composite materials $\mathrm{U}$ and $\mathrm{C} 2$ as a function of cycle number.

\section{Undamped Vibrations}

The differential equation of free motion for an undamped beam [22] may be written as:

$$
\rho_{s} \frac{\partial^{2} w_{0}}{\partial t^{2}}+k_{s} \frac{\partial^{4} w_{0}}{\partial x^{4}}=0
$$

where $\varrho_{s}$ is the mass per unit area and $k_{s}$ is the stiffness per unit area given by: 


$$
k_{s}=\frac{1}{D_{11}^{-1}}
$$

Eq. (1) of transverse vibrations may be rewritten in the form:

$$
\frac{\partial^{2} w_{0}}{\partial t^{2}}+\omega_{0}^{2} L^{4} \frac{\partial^{4} w_{0}}{\partial x^{4}}=0
$$

Introducing the natural angular frequency of the undamped beam:

$$
\omega_{0}=\frac{1}{L^{2}} \frac{k_{s}}{\rho_{s}}=\frac{1}{L^{2}} \sqrt{\frac{1}{\rho_{s} D_{11}^{-1}}}=\frac{1}{L^{2}} \sqrt{\frac{E_{x} h^{3}}{12 \rho_{s}}}
$$

The transverse displacement of the beam at point of coordinate $x$ can be derived as the superimposition of the normal modes:

$$
w_{0}(x, t)=\sum_{i=1}^{\infty} X_{i}(x)\left(A_{i} \cos \omega_{i} t+B_{i} \sin \omega_{i} t\right)
$$

where $X_{i}(x)$ is the normal shape of the $i$ th natural mode, $\omega_{i}$ is its angular frequency. The coefficients $A_{i}$ and Bi depend on the initial conditions imposed at time $t=0$.

In the case of free - clamped beam of length $L, X_{i}(x)$ is the beam function:

$$
X_{i}(x)=\cos \lambda_{i} \frac{x}{L}-\cosh \lambda_{i} \frac{x}{L}-\gamma_{i}\left(\sin \lambda_{i} \frac{x}{L}-\sinh \lambda_{i} \frac{x}{L}\right)
$$

where the coefficient $\lambda_{i}$ and $\gamma_{i}$ are reported in Table 2 .

Table 2. Values of the coefficients of the clamped-free beam function.

\begin{tabular}{cccccccr}
\hline $\boldsymbol{i}$ & $\mathbf{1}$ & $\mathbf{2}$ & $\mathbf{3}$ & $\mathbf{4}$ & $\mathbf{5}$ & $\mathbf{6}$ & $\mathbf{7}$ \\
\hline$\lambda_{i}$ & 1.8751 & 4.6941 & 7.8548 & 10.996 & 14.137 & 17.279 & 20.420 \\
$\gamma_{i}$ & 0.7341 & 1.0185 & 0.9992 & 1.000 & 1.000 & 1.000 & 1.000 \\
\hline
\end{tabular}

The angular frequency of mode $i$ is given by:

$$
\omega_{i}=\lambda_{i}^{2} \omega_{0}
$$

\section{Finite Element Method in the Dynamic Analysis}

The flexural vibrations of beams are analyzed by the finite element method [20], using the stiffness matrix and mass matrix of beam element with two degrees of freedom per node as shown in Fig. 2, where: 


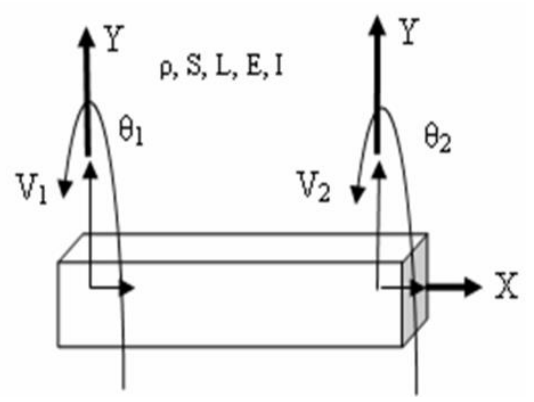

Fig. 2. Beam element with four degrees of freedom.

E: the Young modulus.

I: the moment of inertia of the beam.

$L:$ the length of the beam.

$S$ : the section of the beam.

$\varrho$ : the density.

$$
\begin{gathered}
K_{e}=\frac{E I}{L^{3}}\left[\begin{array}{cccc}
12 & 6 L & -12 & 6 L \\
6 L & 4 L^{2} & -6 L & 2 L^{2} \\
-12 & -6 L & 12 & -6 L \\
6 L & 2 L^{2} & -6 L & 4 L^{2}
\end{array}\right] \\
M_{e}=\frac{\rho S L}{420}\left[\begin{array}{cccc}
156 & 22 L & 54 & -13 L \\
22 L & 4 L^{2} & 13 L & -3 L^{2} \\
54 & 13 L & 156 & -22 L \\
-13 L & -3 L^{2} & -22 L & 4 L^{2}
\end{array}\right]
\end{gathered}
$$

The global matrix of mass and stiffness are obtained by using assembly method:

$$
\begin{aligned}
& K=B^{T} K_{d e s}{ }^{B} \\
& M=B^{T} M_{d e s} B
\end{aligned}
$$

where $B$ is the Boolean matrix and $K_{\text {des }}$ and $M_{\text {des }}$ are unassembled matrix, they contains only elementary matrices of mass and stiffness. The number of elements used in this study is 40 elements.

$$
\begin{gathered}
K_{\text {des }}=\left[\begin{array}{cc}
{\left[K_{e}{ }^{1}\right]} & \\
0 & \ddots\left[K_{e}{ }^{N}\right.
\end{array}\right] \\
M_{\text {des }}=\left[\begin{array}{cc}
{\left[M_{e}{ }^{l}\right]} & 0 \\
0 & \ddots\left[M_{e}{ }^{N}\right.
\end{array}\right]
\end{gathered}
$$

\section{Resolution of the Eigenvalue Problem}

We have two cases where the structure is undamaged or damaged. The equation of motion (undamped and free vibration):

$$
m \ddot{q}(t)+k q(t)=0
$$


The equation (13) can be written in matrix form:

$$
[M]\{\ddot{q}\}+[K]\{q\}=0
$$

where $q$ is the vector of degrees of freedom. For the first case $[K]$ is the global stiffness matrix but for the second case $[K]=\left[K_{D}\right]$, where $\left[K_{D}\right]$ is the global stiffness matrix with damage, that takes into account the decrease in the rigidity of the structure when the loading rates change [20].

The general solution of equation (14) is:

$$
\{q\}=\left\{q_{0}\right\} e^{i \omega t}
$$

By substituting the equation (15) in equation (14), we have:

$$
[K]\left\{q_{0}\right\}=\omega^{2}[M]\left\{q_{0}\right\}
$$

Then, the determinant must be zero:

$$
\operatorname{det}\left([K]-\omega^{2}[M]\right)=0
$$

There are many methods to calculate the eigenvalues; the most of these methods are to write the equation (16) as follows:

$$
[H]\{X\}=\lambda\{X\}
$$

where $[H]$ is a positive and symmetric matrix, it is clear that if we write directly the equation (16) as:

$$
[K]^{-1}[M]\left\{q_{0}\right\}=\frac{1}{\omega^{2}}\left\{q_{0}\right\}
$$

where $[K]^{-1}$ is the inverse of the matrix $[K]$, the symmetry property is not always preserved. Therefore, it is necessary to write the matrix $[K]$ using the Cholesky decomposition:

$$
[K]=[L][L]^{T}
$$

$[L]^{\mathrm{T}}$ is the transpose of the matrix $[L]$ and $[L]$ is a lower triangular matrix. The equation (16) is written:

$$
[L]^{-1}[M][L]^{-T}[L]\left\{q_{0}\right\}=\frac{1}{\omega^{2}}[L]\left\{q_{0}\right\}
$$

By writing equation (21) as similar form as equation (16):

$$
\begin{gathered}
{[H]=[L]^{-1}[M][L]^{-T}} \\
\{X\}=[L]\left\{q_{0}\right\} \\
\lambda=\frac{1}{\omega^{2}}
\end{gathered}
$$




\section{Numerical Evaluation of Damping}

The calculation of structural damping factors of modal energies for the first three modes of vibration of the structure is done by evaluating the ratio of the strain energies of beam for damaged and undamaged cases $[20,21]$.

The modal strain energy of the beam for the undamaged case is given by:

$$
U_{n}=\frac{1}{2}[q]^{T}[K][q]
$$

with:

$[K]:$ Stiffness matrix;

$[q]$ : Eigenvector of displacement.

The modal strain energy for damaged case is given by:

$$
U_{n D}=\frac{1}{2}\left[q_{D}\right]^{T}\left[K_{D}\right]\left[q_{D}\right]
$$

with:

$\left[K_{D}\right]$ : Stiffness matrix (damaged case);

$\left[q_{D}\right]$ : Eigenvector of displacement (damaged case). by:

The structural damping coefficient [20] for different stages of damage (different loading rates) is given

$$
\eta_{n}=\frac{\Delta U_{n}}{U_{n}}=\frac{U_{n}-U_{n D}}{U_{n}}
$$

with $U_{n}$ and $U_{n D}$ are the modal strain energies for undamaged and damaged case.

\section{Results and Discussions}

The modal analysis of the structure for different loading rates is based on the analytical method used to solve the equation of free vibrations. The programming of this resolution method was performed under the Matlab software. The question we thought about, is there a change in the structural damping for the same material when varying the lengths? The specimens used in tensile testing cycle is $0.20 \mathrm{~m}$. for this, we took the values of length higher and lower than the value quoted above. The values of lengths $(\mathrm{m})$ chosen for both materials studied are: 0.14-0.16-0.18-0.20-0.21-0.22-0.23-0.24.

Before using the programs developed by finite element method under Matlab software and in the absence of experimental values of the natural frequencies of the beams, it was necessary to calculate analytical response described in section 3 to test the effectiveness programs developed.

The results obtained for both materials $\mathrm{U}$ and $\mathrm{C} 2$ for undamaged case ( $0 \%$ loading rate), not subject to any cyclic loading show a rapprochement between the frequencies obtained by the model with those evaluated by analytical.

The decrease in frequency can be used as a means of non-destructive control of composite materials. Simply, we limit ourselves to the first three modes due to congestion of results. For the compute of the damaged stiffness matrix is simulated by replacing the Young's modulus of undamaged structure Eo by another Young's modulus derived from Fig. 1 on the fifth cycle (for loading rate 50\%) and ninth cycle (for loading rate $90 \%)$.

For the material $\mathrm{U}$ :

$$
\text { EOU }=21.08 \mathrm{GPa}
$$

- Loading rate $50 \%$ : 


$$
\frac{E_{50 \%}}{E o_{U}}=0.998 \rightarrow E_{50 \%}={ }^{{ }_{0}} o_{U} * 0.998
$$

- Loading rate $90 \%$ :

$$
\frac{E_{90 \%}}{{ }^{E o} U}=0.99 \rightarrow E_{90 \%}=E o_{U} * 0.99
$$

For the material C2:

$$
\mathrm{EO}_{\mathrm{C} 2}=15.04 \mathrm{GPa}
$$

- Loading rate $50 \%$ :

$$
\frac{E_{50 \%}}{{ }^{E o}{ }_{C 2}}=0.96 \rightarrow E_{50 \%}={ }^{E o} C 2 * 0.96
$$

\begin{tabular}{|c|c|c|c|c|}
\hline \multirow[t]{2}{*}{$\begin{array}{l}\text { Length of } \\
\text { beam (m) }\end{array}$} & \multirow[t]{2}{*}{$\begin{array}{l}\text { Analytical } \\
\text { Response } \\
\text { (Hz) }\end{array}$} & \multicolumn{3}{|c|}{$\begin{array}{r}\text { Modeling frequencies } \\
\text { with Different loading } \\
\text { rates }(\mathrm{Hz})\end{array}$} \\
\hline & & $0 \%$ & $50 \%$ & $90 \%$ \\
\hline \multirow{3}{*}{$\mathrm{L} 1=0.140$} & 38.453 & 36.684 & 36.592 & 36.5 \\
\hline & 346.08 & 352.12 & 351.24 & 350.36 \\
\hline & 961.33 & 933.16 & 930.83 & 928.49 \\
\hline \multirow{3}{*}{$\mathrm{L} 2=0.160$} & 29.441 & 28.086 & 28.016 & 27.945 \\
\hline & 264.97 & 269.59 & 268.92 & 268.24 \\
\hline & 736.02 & 714.45 & 712.67 & 710.87 \\
\hline \multirow{3}{*}{$\mathrm{L} 3=0.180$} & 23.262 & 22.192 & 22.136 & 22.08 \\
\hline & 209.36 & 213.01 & 212.48 & 211.95 \\
\hline & 581.55 & 564.51 & 563.09 & 561.68 \\
\hline \multirow{3}{*}{$\mathrm{L} 4=0.200$} & 18.842 & 17.975 & 17.93 & 17.885 \\
\hline & 169.58 & 172.54 & 172.11 & 171.68 \\
\hline & 471.05 & 457.25 & 456.11 & 454.96 \\
\hline \multirow{3}{*}{$\mathrm{L} 5=0.210$} & 17.09 & 16.304 & 16.263 & 16.222 \\
\hline & 153.81 & 156.5 & 156.11 & 155.72 \\
\hline & 427.26 & 414.74 & 413.7 & 412.66 \\
\hline \multirow{3}{*}{$\mathrm{L} 6=0.220$} & 15.572 & 14.855 & 14.818 & 14.781 \\
\hline & 140.15 & 142.6 & 142.24 & 141.88 \\
\hline & 384.3 & 377.89 & 376.95 & 303.47 \\
\hline \multirow{3}{*}{$\mathrm{L} 7=0.230$} & 14.247 & 13.592 & 13.558 & 13.524 \\
\hline & 128.23 & 130.47 & 130.14 & 129.81 \\
\hline & 356.18 & 345.75 & 344.88 & 344.01 \\
\hline \multirow{3}{*}{$\mathrm{L} 8=0.240$} & 13.085 & 12.483 & 12.451 & 12.42 \\
\hline & 117.76 & 119.82 & 119.52 & 119.22 \\
\hline & 327.70 & 317.53 & 316.74 & 315.94 \\
\hline
\end{tabular}

- Loading rate $90 \%$ :

$$
\frac{E_{90 \%}}{{ }^{E o}{ }_{C 2}}=0.92 \rightarrow E_{90 \%}={ }^{E o_{C 2}} * 0.92
$$

Table 3. Frequencies obtained by the model and analytical method for the material U. 
Tables 3-4 provide information on the evolution of the first three modes of the structure under the action of different loading rate and shows also the frequencies obtained by the model and the analytical response for different lengths studied. The steps to calculate them are:

- First, we calculate the natural frequencies of the structure for different lengths as to be compared later with the frequencies obtained by the model for different loading rate $(50 \%-90 \%)$,

- The frequencies obtained by the model are calculated by the finite element method,

- Comparing the natural frequencies obtained by the model for different loading rate $(0 \%, 50 \%$ and $90 \%$ ), we observed that has been a decrease in frequency when the loading rate increases $[18,19]$ confirm the decrease of the Young's modulus shown in Fig. 1. This is very important for the behavior of composite materials during their service. This can be used as a control of loss of stiffness of the structure and subsequently its life time. These observations are the same for both materials $\mathrm{U}$ and $\mathrm{C} 2$.

Table 4. Frequencies obtained by the model and analytical method for the material C2.

\begin{tabular}{|c|c|c|c|c|}
\hline \multirow[t]{2}{*}{$\begin{array}{l}\text { Length of } \\
\text { beam }(m)\end{array}$} & \multirow[t]{2}{*}{$\begin{array}{c}\text { Analytical } \\
\text { Response } \\
\text { (Hz) }\end{array}$} & \multicolumn{3}{|c|}{$\begin{array}{r}\text { Modeling frequencies } \\
\text { with Different loading } \\
\text { rates }(\mathrm{Hz})\end{array}$} \\
\hline & & $0 \%$ & $50 \%$ & $90 \%$ \\
\hline \multirow{3}{*}{$\mathrm{L} 1=0.140$} & 32.480 & 30.986 & 30.518 & 29.882 \\
\hline & 292.320 & 297.430 & 292.930 & 286.830 \\
\hline & 812.010 & 788.220 & 776.300 & 760.130 \\
\hline \multirow{3}{*}{$\mathrm{L} 2=0.160$} & 24.868 & 23.724 & 23.365 & 22.878 \\
\hline & 223.810 & 227.720 & 224.280 & 219.600 \\
\hline & 621.690 & 603.480 & 594.360 & 581.970 \\
\hline \multirow{3}{*}{$\mathrm{L} 3=0.180$} & 19.649 & 18.745 & 18.461 & 18.077 \\
\hline & 176.840 & 179.930 & 177.210 & 173.510 \\
\hline & 491.220 & 476.820 & 469.620 & 459.83 \\
\hline \multirow{3}{*}{$\mathrm{L} 4=0.200$} & 15.915 & 15.183 & 14.954 & 14.642 \\
\hline & 143.240 & 145.740 & 143.540 & 140.550 \\
\hline & 397.880 & 386.230 & 380.390 & 372.460 \\
\hline \multirow{3}{*}{$\mathrm{L} 5=0.210$} & 14.436 & 13.772 & 13.563 & 13.281 \\
\hline & 129.920 & 132.190 & 130.190 & 127.480 \\
\hline & 360.890 & 350.320 & 345.020 & 337.840 \\
\hline \multirow{3}{*}{$\mathrm{L} 6=0.220$} & 13.153 & 12.548 & 12.358 & 12.101 \\
\hline & 118.380 & 120.450 & 118.630 & 116.150 \\
\hline & 328.830 & 319.200 & 314.370 & 307.820 \\
\hline \multirow{3}{*}{$\mathrm{L} 7=0.230$} & 12.034 & 11.481 & 11.307 & 11.072 \\
\hline & 108.310 & 110.200 & 108.540 & 106.270 \\
\hline & 300.860 & 292.040 & 287.630 & 281.640 \\
\hline \multirow{3}{*}{$\mathrm{L} 8=0.240$} & 11.052 & 10.544 & 10.384 & 10.168 \\
\hline & 99.471 & 101.21 & 99.679 & 97.602 \\
\hline & 276.310 & 268.21 & 264.160 & 258.660 \\
\hline
\end{tabular}

The analytical response represents the first three natural modes for a beam clamped at one and free at the other. They are calculated as expressed in section 3 above for to make a comparison between the frequencies obtained by the finite element method and saw the precision of the frequencies found by the model with those calculated analytically. The increase of structural damping indicates simply the maximum values it can attain, in the same way the decrease of structural damping indicates the minimum values it can attain. 


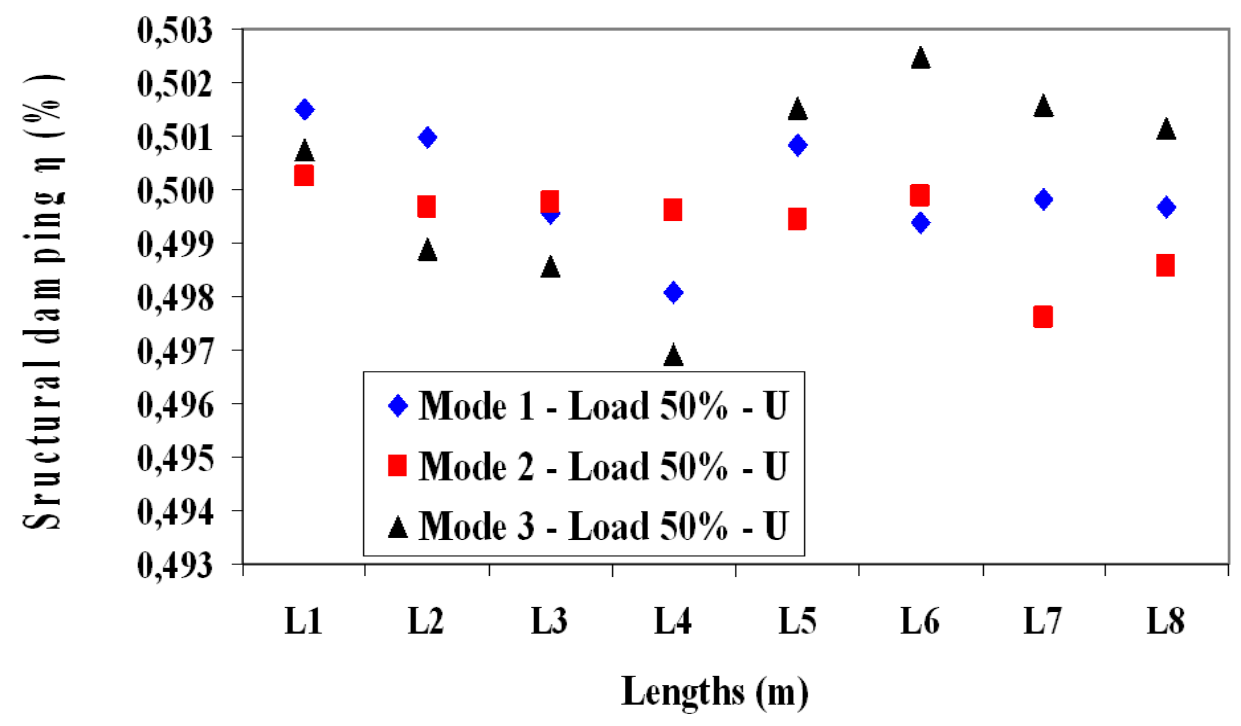

Fig. 3. Modeling results obtained for the damping as function of the length for $\mathrm{U}$ material in the case: load $50 \%$.

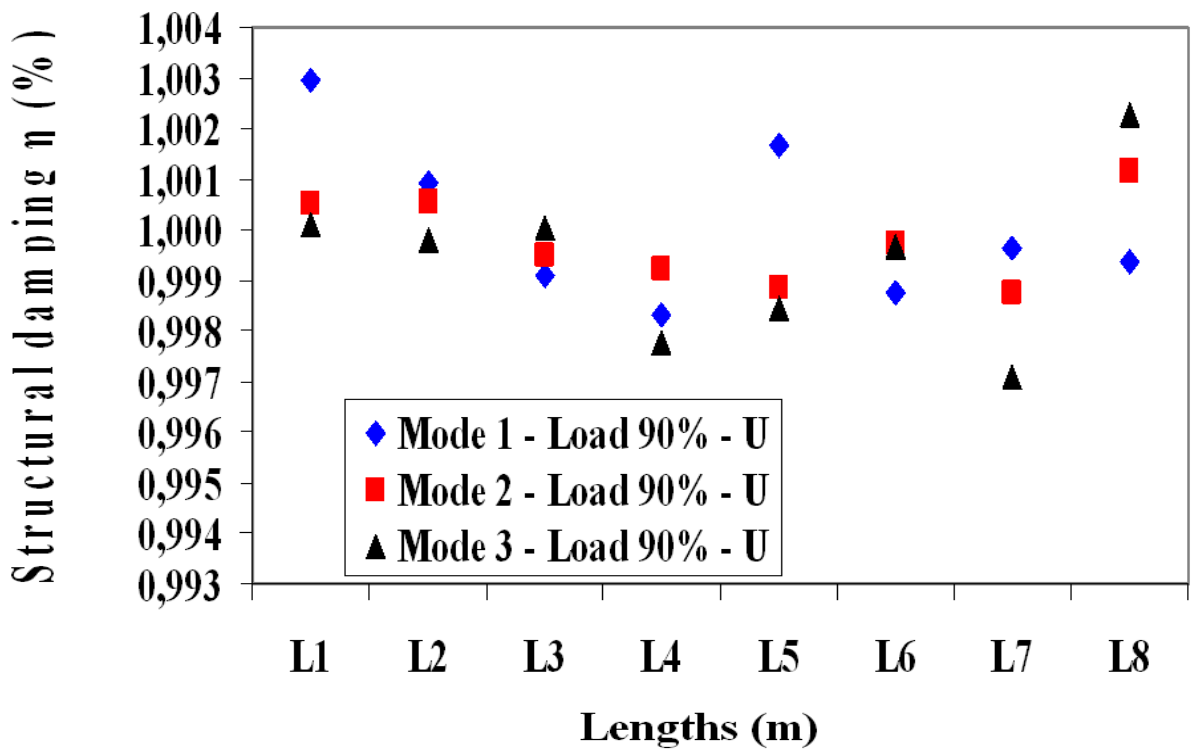

Fig. 4. Modeling results obtained for the damping as function of the length for $\mathrm{U}$ material in the case: load $90 \%$. 


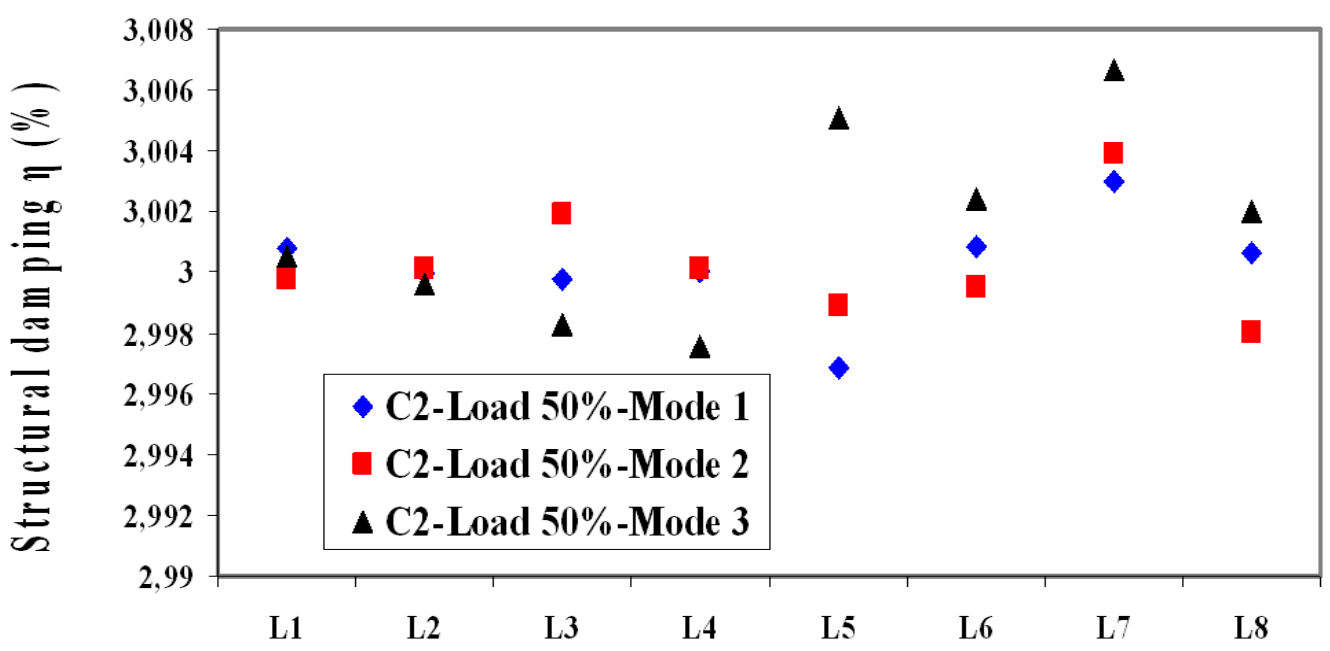

\section{Lengths (m)}

Fig. 5. Modeling results obtained for the damping as function of the length for $\mathrm{C} 2$ material in the case: load $50 \%$.

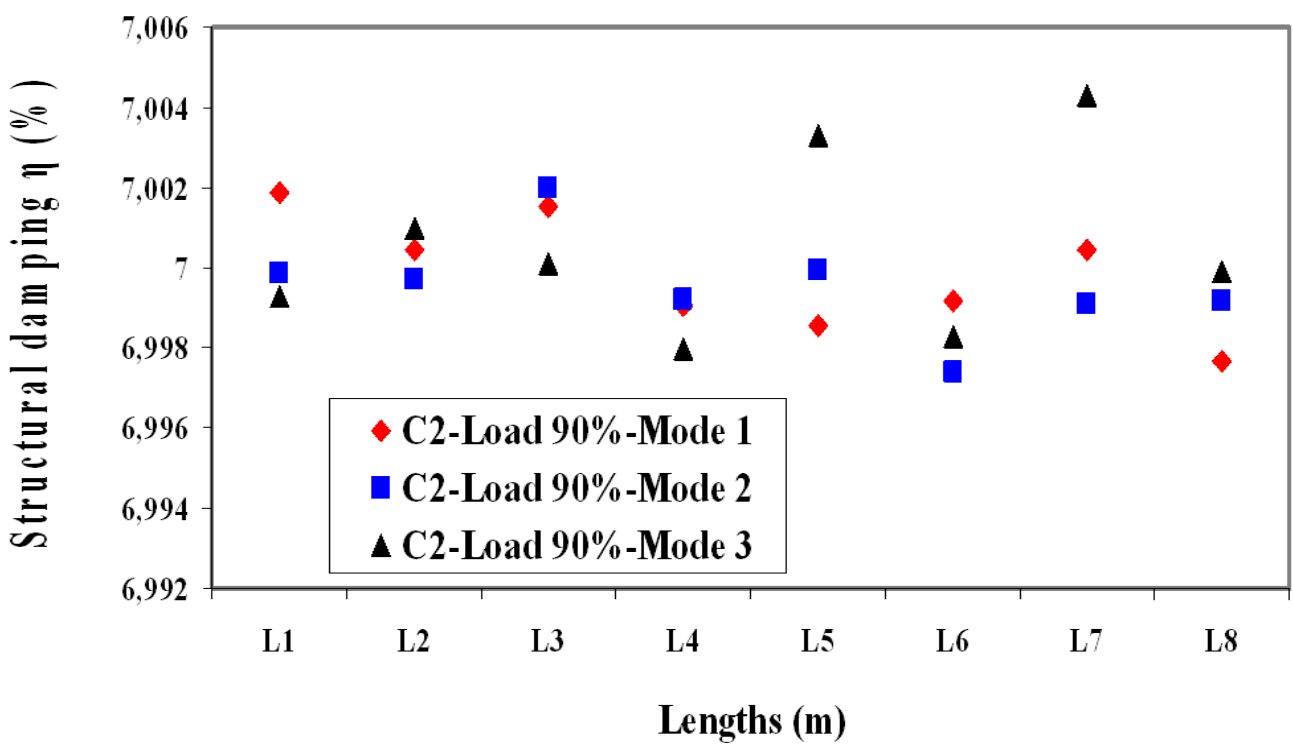

Fig. 6. Modeling results obtained for the damping as function of the length for $\mathrm{C} 2$ material in the case: load $90 \%$.

Figures 3, 6 report the results deduced for the damping by finite element analysis for the first three modes. The evaluation of laminate damping by modeling takes account of the variation of the structural damping $\eta$ with length [23]. We have two cases:

When the loading rate is $50 \%$ :

For U: Figure 3 shows an increase in damping $(0.5025 \%)$ when the length increases except for L4; we observe a slight decrease in damping $(0.497 \%)$.

For C2: Figure 5 shows a slight increase in damping (3.001\%) for $L 1$ and becomes more important for the length $L 7$ (3.007\%). For the second and the third mode, we observe an increase in damping when the length increases except for L5 $(2.997 \%)$.

When the loading rate is $90 \%$ :

For U: Figure 4 shows an increase in damping $(1.003 \%)$ when the length increases except for L7; we observe a slight decrease in damping $(0.997 \%)$. 
For C2: Figure 6 shows an increase in damping (7.005\%) when the length increases except for L6; we observe a slight decrease in damping (6.997\%).

\section{Conclusions}

For the case of dynamic analysis, the finite element technique was used to calculate modal analysis in composite structures. Of particular interest are the resulting modal parameters such as frequencies and damping. The strain energy calculation is performed by using a finite element analysis of the vibrations of a composite structure. Figures 3-6 give us information about the evolution of structural damping value for each mode which is not constant and varies in length to another. We can have structural damping values for material $\mathrm{U}$ an interval for loading rate $50 \%$ between $0.497 \%$ and $0.5025 \%$, and another an interval for loading rate $90 \%$ between $0.997 \%$ and $1.003 \%$. While for the material C2, we have between $3.001 \%$ and $3.007 \%$ for loading rate $50 \%$ and between $6.997 \%$ and $7.005 \%$ for loading rate $90 \%$. The decrease in frequency of different loading rates shows the loss of stiffness for the height lengths of beams studied. The loss factors of the composite materials can be deduced by applying modeling to the flexural vibrations of free-clamped beams. The results deduced from the damping by finite element analysis for the first three modes shows that the evaluation of laminate damping takes account the variation of the structural damping $\eta$ with lengths for the two laminate beams $\mathrm{U}$ and $\mathrm{C} 2$. The damping begins by cracks and leads to a loss of stiffness witch can be appreciable when the loading rate increases; this should be taken into account in all analysis. The decrease in frequency can be considered as an important tool test for damage detection.

\section{References}

[1] R. F. Gibson, "Dynamic mechanical properties of advanced composite materials and structures: a review," Shock Vibration Digest, vol. 19, no.7, pp.13-22, 1987.

[2] C. D. Johnson, and D. A. Kienholz, "Finite element prediction of damping in structures with constrained viscoelastic layers," $A L A A$, vol. 20, no.9, pp.1284-90, 1984.

[3] S. J. Hwang, and R. F. Gibson, "Micromechanical modeling of damping in discontinuous fiber composites using strain energy/ finite element approach," J. Eng. Mat. Tech., vol. 109, pp.47-52, 1987.

[4] J. M. Berthelot, Composite Materials, Mechanical Behaviour and Structural Analysis, Springer, New York, 1999.

[5] R. F. Gibson, and R. A. Plunkett, "Dynamic stiffness and damping of fibre-reinforced composite materials ," Shock Vibration Digest, vol. 9, no.2, pp.9-17, 1977.

[6] R. F. Gibson, D. G. Wilson, "Dynamic mechanical properties of fibre-reinforced composite materials," Shock Vibration Digest, vol. 11, no.10, pp. 3-11, 1979.

[7] R. D. Adams, and D. G. C. Bacon, "Effect of fibre orientation and laminate geometry on the dynamic properties of CFRP," J. Compos. Mater., vol. 7, pp. 402-8, 1973.

[8] R. G. Ni, and R. D. Adams, "The damping and dynamic moduli of symmetric laminated composite beams. Theoretical and experimental results," Compos. Sci. Technol., vol. 18, pp. 104-21,1984.

[9] R. D. Adams, and M. R. Maheri, "Dynamic flexural properties of anisotropic fibrous composite beams," Compos. Sci. Technol., vol. 50, pp. 497-514, 1994.

[10] D. X. Lin, R. Ni, and R. D. Adams, "Prediction and measurement of the vibrational parameters of carbon and glass-fibre reinforced plastic plates," J. Compos. Mater., vol. 18, pp. 132-52, 1984.

[11] M. R. Maheri, and R. D. Adams, "Finite element prediction of modal response of damped layered composite panels," Compos. Sci. Technol., vol. 55, pp. 13-23, 1995.

[12] J. H. Yim, "A damping analysis of composite laminates using the closed form expression for the basic damping of Poisson's ratio," Compos. Struct., vol. 46, pp. 405-11, 1999.

[13] J. H. Yim, and B. Z. Jang, "An analytical method for prediction of the damping in symmetric balanced laminates composites," Polymer Compos., vol. 20, no.2, pp. 192-9, 1999.

[14] J. H. Yim Jr., and J. W. Gillespie, "Damping characteristics of $0^{\circ}$ and $90^{\circ}$ AS4/3501-6 unidirectional laminates including the transverse shear effect," Compos. Struct., vol. 50, pp. 217-25, 2000.

[15] D. Young, "Vibration of rectangular plates by the Ritz method," J. Appl. Mech.,vol. 17, pp. 448-53, 1950.

[16] J. M. Berthelot, and Y. Sefrani, "Damping analysis of unidirectional glass and Kevlar fibre composites," Compos. Sci. Technol., vol. 64, pp. 1261-78, 2004. 
[17] J. M. Berthelot, "Damping analysis of laminated beams and plates using the Ritz method," Compos. Struct., vol. 74, pp. 186-201, 2006.

[18] H. A. Whitworth, "A stiffness degradation model for composite laminates under fatigue loading," Compos. Struct., vol. 40, no.2, pp. 95-101, 1998.

[19] H. A. Whitworth, "Evaluation of residual strength degradation in composite laminates under fatigue loading," Compos. Struct., vol. 48, pp. 261-264, 2000.

[20] M. N. Amrane, and F. Sidoroff, "Residual modal energy evaluating of fatigue damaged composite structure," Mechanika., vol. 17, no.1, pp. 45-49, 2011.

[21] A. Elmahi, M. Assarar, Y. Sefrani, and J. M. Berthelot, "Damping analysis of orthotropic composite materials and laminates," Composite: part B, vol. 39, pp. 1069-1076, 2008.

[22] J. M. Berthelot, and Y. Sefrani, "Temperature effect on the damping properties of unidirectional glass fibre composites," Composites: part B, vol. 37, pp. 346-355, 2006.

[23] S. J. Hwang, and R.F. Gibson, "The effect of three-dimensional states of stress on damping of laminated composites," Compos. Sci. Techno., vol. 41, pp. 379-393, 1991. 
